\title{
UTILIZAÇÃO DE RESÍDUO DE ESTAÇÃO DE TRATAMENTO DE ESGOTO (ETE) NA ADSORÇÃO DE AZUL DE METILENO.
}

\author{
N. L. SANTOS, C. N. BERNARDO, G. R. ROSA e T. J. LOPES* \\ Universidade Federal do Rio Grande - FURG, Escola de Química e Alimentos - EQA \\ *E-mail para contato: tjlopes@furg.br
}

\begin{abstract}
RESUMO - A expansão populacional e a urbanização não planejada têm contribuído drasticamente para o aumento da poluição ambiental, principalmente pela evolução industrial. Este crescimento acarretou em melhoria da qualidade de vida de muitas pessoas, todavia, também promoveu o aumento da produção de resíduos tóxicos industriais, despejo de efluentes e resíduos agrícolas. Em relação às águas residuais, a má disposição final de efluentes tende a gerar grande preocupação, principalmente pela contaminação por corantes. O presente trabalho teve como objetivo principal, desenvolver e estudar a possibilidade de utilizar adsorventes alternativos, com o resíduo de estação de tratamento de esgoto (ETE) na adsorção do corante azul de metileno. Foram avaliados os fatores que afetam a obtenção e a utilização em processos de tratamento destes efluentes. A variável tempo não apresentou influência sobre o poder de adsorção, enquanto que a temperatura contribuiu de forma positiva e significativa no processo de adsorção na faixa de 500 a $700^{\circ} \mathrm{C}$. Portanto, estes resultados iniciais, indicam que o ETE se credencia como adsorvente para tratamento de efluentes aquosos que possuam o corante de azul de metileno.
\end{abstract}

\section{INTRODUÇÃO}

A contaminação das fontes hídricas é um fator ambiental em discussão atualmente. $\mathrm{O}$ uso ineficiente, a superexploração das reservas naturais de água e o descarte inadequado de componentes químicos são uns dos problemas enfrentados. Segundo a ONU (Organização das Nações Unidas), a escassez de água pode limitar crescimento econômico nas próximas décadas, em razão de que as regiões dependentes de matéria-prima com o uso intensivo de água como a mineração e a agricultura, são diretamente afetadas (Leal et al., 2012).

O efluente das indústrias têxteis é uma fonte potencial de resíduos químicos, principalmente corantes sintéticos, que são prejudiciais para o meio ambiente. No ano de 2015, segundo a ABIT (Associação Brasileira da Indústria Têxtil e de Confecção), o setor têxtil do Brasil produziu 1,8 milhão de toneladas de roupas. Além dos detritos de resíduos sólidos e o uso de corantes afetam o meio ambiente. Nessa atividade, são usados cerca de 10.000 corantes e pigmentos diferentes, representando um consumo de $8 \times 10^{5}$ toneladas no mundo anualmente, dentre essas, 26.500 toneladas apenas no Brasil (Silveira et al., 2012). 
Cerca de $20 \%$ dos corantes usados pela indústria têxtil são descartados como efluentes, por causa da incompleta fixação do corante da fibra do tecido (Kunz et al., 2002; Dallago e Smaniotto, 2005).

O azul de metileno é um corante muito utilizado nas indústrias para diversos fins, como a fabricação de papel e de tecidos. $\mathrm{O}$ descarte inadequado nos rios e lagos diminui a transparência das águas limitando a passagem dos raios solares, diminuindo a atividade fotossintética natural, provocando alterações na biota aquática, prejudicando todo o ecossistema (Kunz et al., 2002; Silva \& Oliveira, 2012). Além de que, a alta exposição ao azul de metileno pode causar efeitos prejudiciais diretamente à saúde como aumento do batimento cardíaco, dor de cabeça intensa, náuseas, vômitos, diarreia e necrose do tecido humano (Oliveira et al., 2013).

Outra atividade de geração de resíduos é o setor de tratamento de esgoto, onde são geradas toneladas de detritos todos os anos. Segundo o IBGE (Instituto Brasileiro de Geografia e Estatística) cerca de 14,5 milhões de metros cúbicos de esgoto são gerados diariamente no Brasil, dos quais 5,1 milhões de metros cúbicos são tratados (Godecke et al., 2012).

A estação de tratamento de esgoto (ETE) removem as cargas poluentes do esgoto sanitário através de processos físicos, químicos ou biológicos devolvendo para o meio ambiente um efluente tratado seguindo as normas ambientais. Segundo a Sabesp (Companhia de Saneamento Básico do Estado de São Paulo), os efluentes tratados são descartados em aterros sanitários (Sabesp, 2017).

Existem diversos métodos para o tratamento de efluente industrial e a busca de inovação tem chamado bastante atenção no meio científico e tecnológico nos últimos anos, a fim de minimizar os custos e problemas operacionais dos convencionais (Panizza et al., 2008). Sendo que a adsorção é uma técnica de grande potencial para ser utilizada no tratamento de efluentes industriais, permitindo uma efetiva separação dos contaminantes químicos, sendo um processo que de baixo custo (Braga et al., 2008). Esse processo consiste em um sistema que apresenta um adsorbato (substância ou componente) presente no fluido (gasoso ou líquido), o qual será separado por um adsorvente (sólido) através da interação com os sítios ativos presentes nas superfícies do material.

A adsorção utilizando como adsorvente o resíduo gerado pelo ETE propicia vantagens, principalmente, econômicas. Sendo um processo com baixo investimento inicial diante dos processos convencionais, que utilizam o carvão ativo como adsorvente, no qual gera elevados custos para a indústria. Portanto, este trabalho tem como objetivo realizar um estudo preliminar da eficácia da adsorção do corante azul de metileno em resíduo de tratamento de esgoto (ETE). Ambas as substâncias residuais, nas quais poderiam ser descartadas de forma inadequada, poluindo aquíferos naturais, lençóis freáticos entre outros, e também, podendo ocasionar um aumento no montante dos aterros sanitários. 


\section{MATERIAL E MÉTODOS}

\subsection{Resíduo de Estação de Tratamento de Esgoto (ETE)}

O material utilizado como adsorvente foi adquirido numa Estação de Tratamento de Esgoto (ETE) situada na cidade de Rio Grande - RS, no ano de 2016. A partir do resíduo coletado obtiveram-se quatro amostras de $15 \mathrm{~g}$ e foram colocadas em cápsulas de porcelana para ser submetido a tratamento térmico em forno tipo mufla com temperatura e tempo predeterminado.

\subsection{Corante azul de metileno}

O corante utilizado no desenvolvimento do trabalho foi o azul de metileno, um corante catiônico muito utilizado na indústria têxtil, escolhido com o objetivo de avaliar a atuação do resíduo de ETE no tratamento de efluentes industriais via processo de adsorção. A concentração deste corante foi medida via espectrofotometria, na faixa do visível, utilizando um comprimento de onda de $665 \mathrm{~nm}$ (Castro et al., 2009; Merg et al., 2010). A curva padrão obtida foi de [Concentração de corante] $=5,4458$ [Absorbância] (com coeficiente de determinação de $\left.\mathrm{R}^{2}=0,9975\right)$.

\subsection{Planejamento experimental para o tratamento térmico}

O resíduo de ETE foi submetido a um tratamento térmico para avaliar a influência das seguintes variáveis de processo: A) Temperatura e B) tempo; com seus respectivos níveis de variação mostrados na Tabela 1 . Foi adotado um planejamento experimental fatorial completo $2^{2}$. Posteriormente, à realização do planejamento, aplicou-se a Metodologia das Superfícies de Resposta (MSR) com o objetivo de obter as condições ótimas de operação.

Tabela 1 - Fatores e níveis estudados no tratamento térmico das amostras.

\begin{tabular}{|l|cc|}
\hline & \multicolumn{2}{|c|}{ Níveis codificados } \\
\cline { 2 - 3 } & -1 & +1 \\
\hline Temperatura $\left({ }^{\circ} \mathrm{C}\right)$ & 300 & 500 \\
\hline Tempo (minutos) & 20 & 40 \\
\hline
\end{tabular}

O poder de adsorção do resíduo de ETE após passar pelo tratamento térmico foi avaliado para cada ensaio, utilizando-se como substância a ser adsorvida o corante azul de metileno.

\subsection{Ensaios em batelada de adsorção}

Os ensaios em sistema estático (batelada) foram realizados em recipientes com um volume de $50 \mathrm{~mL}$ de solução de corante azul de metileno, com concentração inicial de 30 ppm e $1 \mathrm{~g}$ de adsorvente. Os frascos foram introduzidos em uma mesa agitadora orbital Oxilab, modelo OXI - 304, a uma temperatura de $30^{\circ} \mathrm{C}$ e agitação de $100 \mathrm{rpm}$. Após 4 horas de 
realização do processo de adsorção foi retirada uma alíquota do sobrenadante para determinação da concentração de corante via espectroscopia visível.

\section{RESULTADOS E DISCUSSÃO}

O planejamento experimental realizado para o tratamento térmico do resíduo de ETE é apresentado na Tabela 2, juntamente com a concentração mássica de corante azul de metileno retida no adsorvente.

Tabela 2 - Planejamento experimental para tratamento térmico do resíduo de ETE e as respectivas respostas para adsorção do corante.

\begin{tabular}{|c|c|c|c|c|}
\hline Ensaios & \multicolumn{2}{|c|}{ Fatores } & \multicolumn{2}{c|}{ Variável Resposta } \\
\cline { 2 - 5 } & $\begin{array}{c}\text { Temperatura } \\
\left({ }^{\circ} \mathrm{C}\right)\end{array}$ & $\begin{array}{c}\text { Tempo } \\
(\mathrm{min})\end{array}$ & $\begin{array}{c}\text { Massa de } \\
\text { adsorvente tratada } \\
\text { termicamente }(\mathrm{g})\end{array}$ & $\begin{array}{c}\text { Concentração mássica } \\
\text { de corante no } \\
\text { adsorvente }(\mathrm{mg} / \mathrm{g})\end{array}$ \\
\hline 1 & $-1(300)$ & $-1(20)$ & 8,994 & 0,0419 \\
\hline 2 & $1(500)$ & $-1(20)$ & 6,498 & 1,222 \\
\hline 3 & $-1(300)$ & $1(40)$ & 9,087 & 0,0475 \\
\hline 4 & $1(500)$ & $1(40)$ & 6,06 & 1,144 \\
\hline
\end{tabular}

Através dos resultados obtidos na Tabela 2 realizou-se uma análise estatística dos efeitos das duas varáveis independentes (temperatura e tempo), sobre a variável resposta concentração mássica de corante no adsorvente. A escolha do modelo com melhor ajuste foi feita a partir da análise de variância (ANOVA) e do coeficiente de determinação $\left(\mathrm{R}^{2}\right)$. $\mathrm{O}$ modelo empírico a ser utilizado é o de efeitos principais e sem interações.

Com o modelo empírico realizou-se a análise dos efeitos em relação à variável resposta, que se pode observada na Tabela 3.

Tabela 3. Efeitos e índices estatísticos para o modelo empírico com efeitos principais e sem interações $\left(\mathrm{R}^{2}=0,9986\right)$.

\begin{tabular}{|lccccc|}
\hline & Efeito & Desvio Padrão & Valor de $p$ & \multicolumn{2}{c|}{ Limites de confiança } \\
& & & & $-95 \%$ & $+95 \%$ \\
\hline Média/Interações & 0,6139 & 0,0209 & 0,0217 & 0,3483 & 0,8794 \\
(A) Temperatura & 1,1383 & 0,0418 & 0,0234 & 0,6072 & 1,6694 \\
(B) Tempo & $-0,0362$ & 0,0418 & 0,5456 & $-0,5673$ & 0,4949 \\
\hline
\end{tabular}

Analisando-se a Tabela 3, observa-se que os valores dos efeitos para as variáveis temperatura e tempo, apresentam sinal algébrico diferente. No que diz respeito à temperatura, quanto maior o seu valor durante o processo de tratamento térmico do ETE, maior será a remoção de corante azul de metileno no processo de adsorção. Em relação ao tempo, o comportamento foi contrário, o adsorvente de resíduo de ETE com maior tempo de residência no forno tipo mufla apresentou menor performance na remoção do corante em solução. 
Também, pode-se observar que dentro do intervalo de confiança de 95\% utilizado, a temperatura e a média são significativas estatisticamente, apresentando um valor de $\mathrm{p}$ (probabilidade) inferior a 5\%, dentro do nível de significância adotado de 5\% ( $\alpha$ ).

A partir da regressão foram obtidos os coeficientes do modelo empírico para a concentração de corante no adsorvente, o qual é representado pela Equação 1.

$$
\mathbf{C}=0,613850+0,569150 \mathbf{A}-0,018100 \mathbf{B}
$$

Em que: $\mathbf{C}=$ Concentração de corante no adsorvente de resíduo de ETE após a adsorção; $\mathbf{A}=$ Temperatura utilizada durante o tratamento térmico do adsorvente; e $\mathbf{B}=$ Tempo de residência do adsorvente na Mufla.

A partir da escolha do melhor modelo foi obtido o gráfico das curvas de nível para a variável resposta concentração de corante no sólido, Figura 1.

Figura 1. Curvas de nível para os fatores codificados de temperatura e tempo em relação à resposta concentração de corante no sólido.

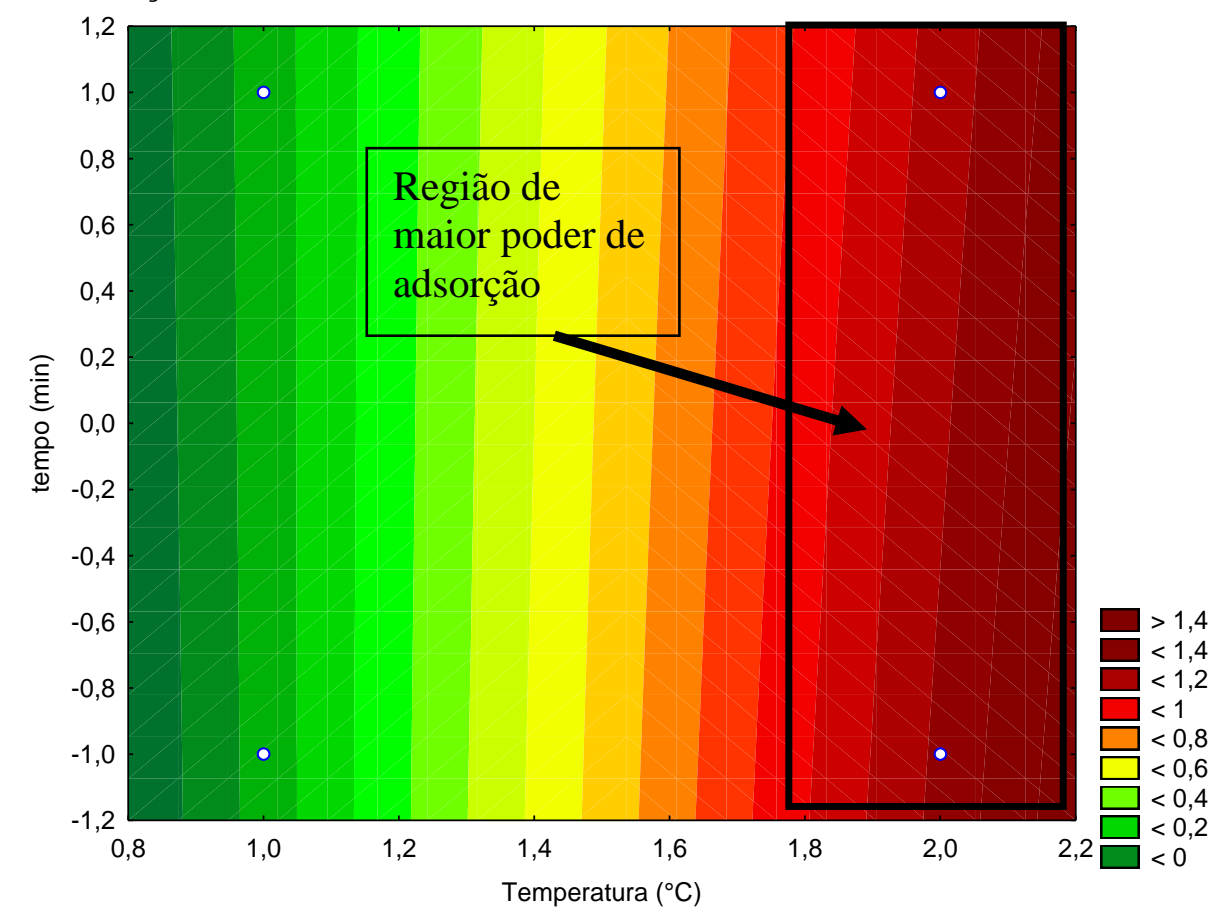

As curvas de níveis (Figura 1) mostram a área em que se estabelece a melhor condição para remoção do corante. A faixa de temperatura de tratamento térmico do adsorvente entre 660 a $740^{\circ} \mathrm{C}$ (níveis 1,8 a 2,2) favoreceu a transferência de corante do líquido para o sólido. Em relação ao tempo esse pouco afetou o sistema, portanto, o modelo não apresenta uma faixa exata que apresente melhor resposta para a remoção de corante.

\section{CONCLUSÕES}

Com o objetivo de encontrar uma alternativa de aproveitamento do resíduo sólido de estações de tratamento de esgoto estudou-se a possibilidade de obtenção de um novo material adsorvente para remoção do corante azul de metileno. 
Através da utilização de técnicas de planejamento experimental, foi possível verificar a influência dos parâmetros tempo e temperatura de tratamento térmico das amostras sobre a capacidade de adsorção. Assim sendo, observou-se que a variável tempo não apresentou influencia sobre o poder de adsorção, enquanto que a temperatura contribuiu de forma positiva e significativa no processo de adsorção na faixa de 500 a $700^{\circ} \mathrm{C}$. Portanto, estes resultados iniciais, indicam que o ETE se credencia como adsorvente para tratamento de efluentes aquosos que possuam o corante de azul de metileno.

\section{AGRADECIMENTOS}

Ao Programa Institucional de Desenvolvimento do Estudante PDE/FURG 2016, pelo auxílio financeiro através da bolsa EPEM.

\section{REFERÊNCIAS}

ABIT, ASSOCIAÇÃO BRASILEIRA DE INDÚSTRIA TÊXTIL E DE CONFECÇÃO Disponível em: <http://www.abit.org.br/cont/perfil-do-setor>, Acesso em 16 de março de 2017.

BORGES, W.G.P.; CAETANO, J.; CELANTE, G.; DRAGUNSKIL D.C.; HONORATO, A.C.; MACHADO J.M.; Biossorção de azul de metileno utilizando resíduos agroindustriais. v. 205-210, p. 1, 2015.

FÁVERE, V.T.; FURLAN, L.; LARANJEIRA, M.C.M.; LONGHINOTTI, E.; Adsorção de azul de metileno e croconato amarelo pelo biopolímero quitina. v. 19 p. 221-224, 1996.

FIGUEIREDO, J.A.S.; GODECKE, M.V.; NAIME, R.H.; O consumo e a geração de resíduos sólidos urbanos no Brasil. v. 8, p. 1700-1712, 2012.

GREGÓRIO, A.M.; HOLZBACH, J.C.; KRAUSER, M.O.; LEAL, P.V.B.; OTONI, E.; SILVA, P.R.; Estudo da adsorção do corante azul de metileno em resíduos de babaçu. v. 3, p. 166-171, 2012.

HONÓRIO, L.M.C.; LUCENAL, G. L.; SANTOS, V.D.; SILVA, A.G.; Remoção de corantes têxteis a partir de soluções aquosas por quitosana modificada com tioacetamida. v. 8, p. 144-154, 2013.

IBGE, INSTITUTO BRASILEIRO DE GEOGRAFIA E ESTATÍSTICA, Disponível em: <http://www.ibge.gov.br/home/presidencia/noticias/27032002pnsb.shtm>, Acesso em 16 de março de 2017.

MELO, M.J.M.; Estudo de métodos de tratamento de efluentes (troca iônica e eletroquímica) separados e sequenciais para eliminação de derivados de petróleo. Dissertação (mestrado), 2014. 